\title{
Derek.
}

$$
\text { DOE/PC-30177-1 }
$$

\section{PULVERIZED-COAL COMBUSTION}

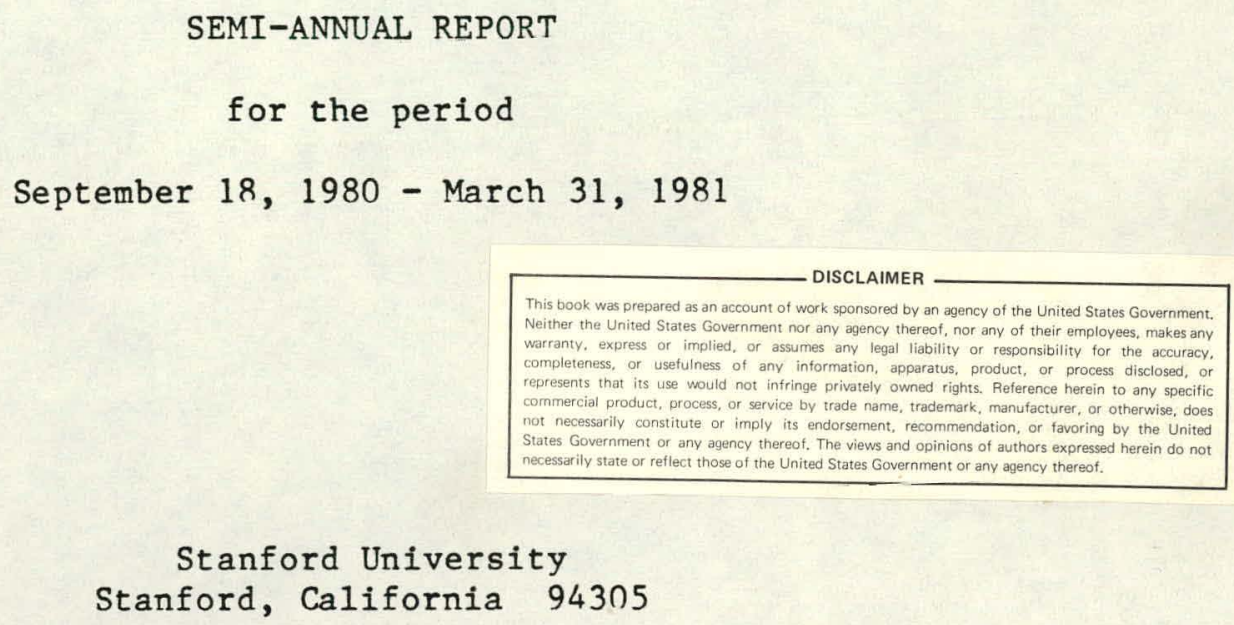

Date Published - April 1981

Prepared for

THE UNITED STATES DEPARTMENT OF ENERGY

Under Contract No. DE-AC22-80PC30177 


\section{DISCLAIMER}

This report was prepared as an account of work sponsored by an agency of the United States Government. Neither the United States Government nor any agency Thereof, nor any of their employees, makes any warranty, express or implied, or assumes any legal liability or responsibility for the accuracy, completeness, or usefulness of any information, apparatus, product, or process disclosed, or represents that its use would not infringe privately owned rights. Reference herein to any specific commercial product, process, or service by trade name, trademark, manufacturer, or otherwise does not necessarily constitute or imply its endorsement, recommendation, or favoring by the United States Government or any agency thereof. The views and opinions of authors expressed herein do not necessarily state or reflect those of the United States Government or any agency thereof. 


\section{DISCLAIMER}

Portions of this document may be illegible in electronic image products. Images are produced from the best available original document. 
PULVERIZED COAL COMBUSTION

\author{
Semi-Annual Report for the \\ , \\ Period September 18, 1980 - March 31, 1981 \\ Contract DE-AC22-80PC30177
}

Prepared for

THE UNITED STATES DEPARTMENT OF ENERGY

Submitted by

Professor C. H. Kruger

This report was prepared as an account of work sponsored by the United States Government. Neither the United States nor the United States Department of Energy, nor any of their employees, makes any warranty, express or implied, or assumes any legal liability or responsibility for the accuracy, completeness, or usefulness of any information, apparatus, product or process disclosed, or represents that its use would not infringe privately owned rights. Reference herein to any specific commercial product, process, or service by trade name, mark, manufacturer, or otherwise, does not necessarily constitute or imply its endorsement, recommendation, or favoring by the United States Government or any agency thereof. The views and opinions of authors expressed herein do not necessarily state or reflect those of the United States Government or any agency thereof.

Apri1, 1981

High Temperature Gasdynamics Laboratory Department of Mechanical Engineering Stanford University 
A flow tube reactor for the study of the reactivity of pulverized coal under controlled conditions has been developed at Stanford University. The reactor system incorporates advanced optical diagnostics as well as probe sampling techniques to measure the reactivity of coals with differing physical and chemical properties. The aim of the research is to provide fundamental data that can be used in the design and development of coal combustion systems. Reactor characterization measurements with a number of diagnostics have shown that the system performs according to design specifications.

In recent experiments, Montana Rosebud coal was found to have a relatively high oxidation reactivity. Marked qualitative differences in oxidation behavior, associated with the rate of volatile evolution, were observed as the gas temperature was increased from about $1100 \mathrm{~K}$ to $1500 \mathrm{~K}$. Electron microscopy analysis showed the development of a complex macropore structure during burnout. The existence of this structure is consistent with preliminary data indicating a dependence of reactivity on particle size differing from that predicted by some theories. 
Abstract.......................................

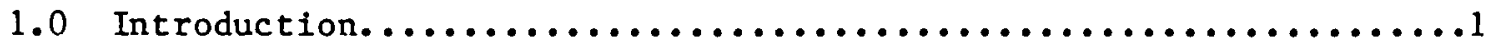

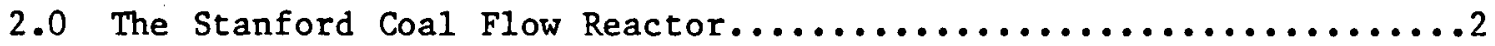

Reactor Design and Characterization.....................

Diagnostics..................................

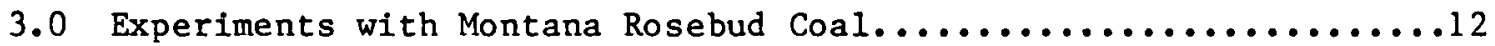

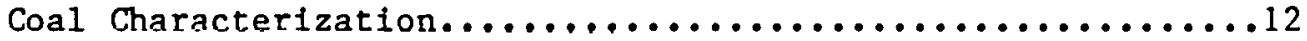

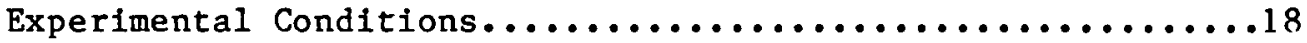

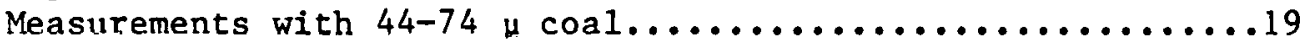

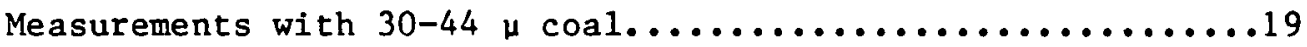

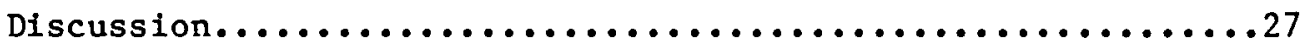

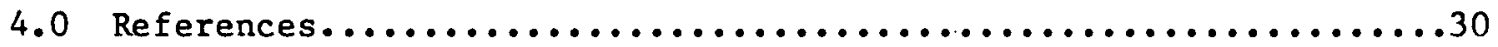

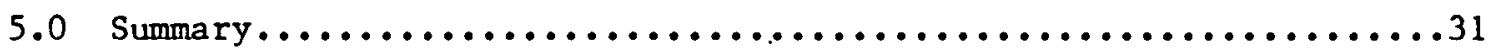




\subsection{INTRODUCTION}

This is the first semi-annual progress report on a research program, "Pulverized Coal Combustion," sponsored by the Department of Energy under Contract DE-AC22-80PC30177 as a part of the advanced Research and Technology Development for Direct Utilization program of the Pittsburgh Energy Technology Center. The goal of this research is to provide fundamental data on pulverized coal combustion, under carefully controlled experimental conditions, that will aid in relating reactivity to the physical and chemical properties of the coal particles and in the prediction of combustion performance for various coals. To this end a coal flow reactor incorporating optical diagnostics and probe sampling techniques has been designed, fabricated, and characterized. Reactivity measurements will be performed with three coals and one char in the temperature range $1500-2000 \mathrm{~K}$, and the results will be interpretted to provide reactivity data for the design and development of coal combustion systems.

Work during the first six months of this contract has been directed to characterization of the flow tube reactor and reactivity measurements of Montana Rosebud coal. In this report, the Stanford Flow Tube Reactor and associated diagnostics are described in Section 2 and initial results from measurements with the Rosebud coal are presented in Section 3. 


\subsection{STANFORD COAL FLOW REACTOR}

Reactor Design and Characterization. The philosophy behind the flow reactor design is based on achieving uniform velocity, temperature, and concentration conditions where one may observe the reactivity of pulverized coal under uniform and known reaction conditions [1]. This approach is in contrast to reactors where temperature, velocity, and concentration fields are complex and vary with reaction time. We feel that isolation of reactivity characteristics is best understood under controlled and uniform reactor conditions.

To achieve this goal, the atmospheric pressure reactor facility is comprised of the following major components (Fig. 1).

1. An arc jet heats argon which expands through a plenum $40 \mathrm{~cm}$ in length.

2. The first plenum is attached to a larger plenum where $\mathrm{O}_{2}$ (for oxidation experiments) and other reactant gases, $\mathrm{CO}_{2}$ and $\mathrm{H}_{2} \mathrm{O}$ (for gasification experiments), are mixed with the argon flow before entering a ceramic contraction cone, which smooths the flow and produces relatively uniform entrance conditions.

3 At the exit of the contraction cone ( $10: 1$ area ratio) a throat section is provided where the pulverized coal and carrier gas are injected perpendicularly to the main flow through small opposed jets. The coal and hot reactant gas are rapidly mixed in the initial portion of a $20 \mathrm{~cm}$ diffuser section before entering the primary reactor sections.

4. From the point of coal injection to the reactor exit an insulating furnace with a temperature capability up to $1600^{\circ} \mathrm{K}$ is used to minimize the axial temperature drop. There are two furnace units of different lengths which can be used separately or in combinaion. Flow reactor characteristics are summarized in Table $I$.

5. Probe and optical measurements can be made at three locations for a given reactor configuration, namely through two $4 \mathrm{~cm}$ diameter access ports and in the free jet at the reactor exit. Given the possible combinations of flow velocity, reactor diameter and length, we obtain the capability of measuring the extent of reaction at times ranging from less than 10 to 300 msec. 


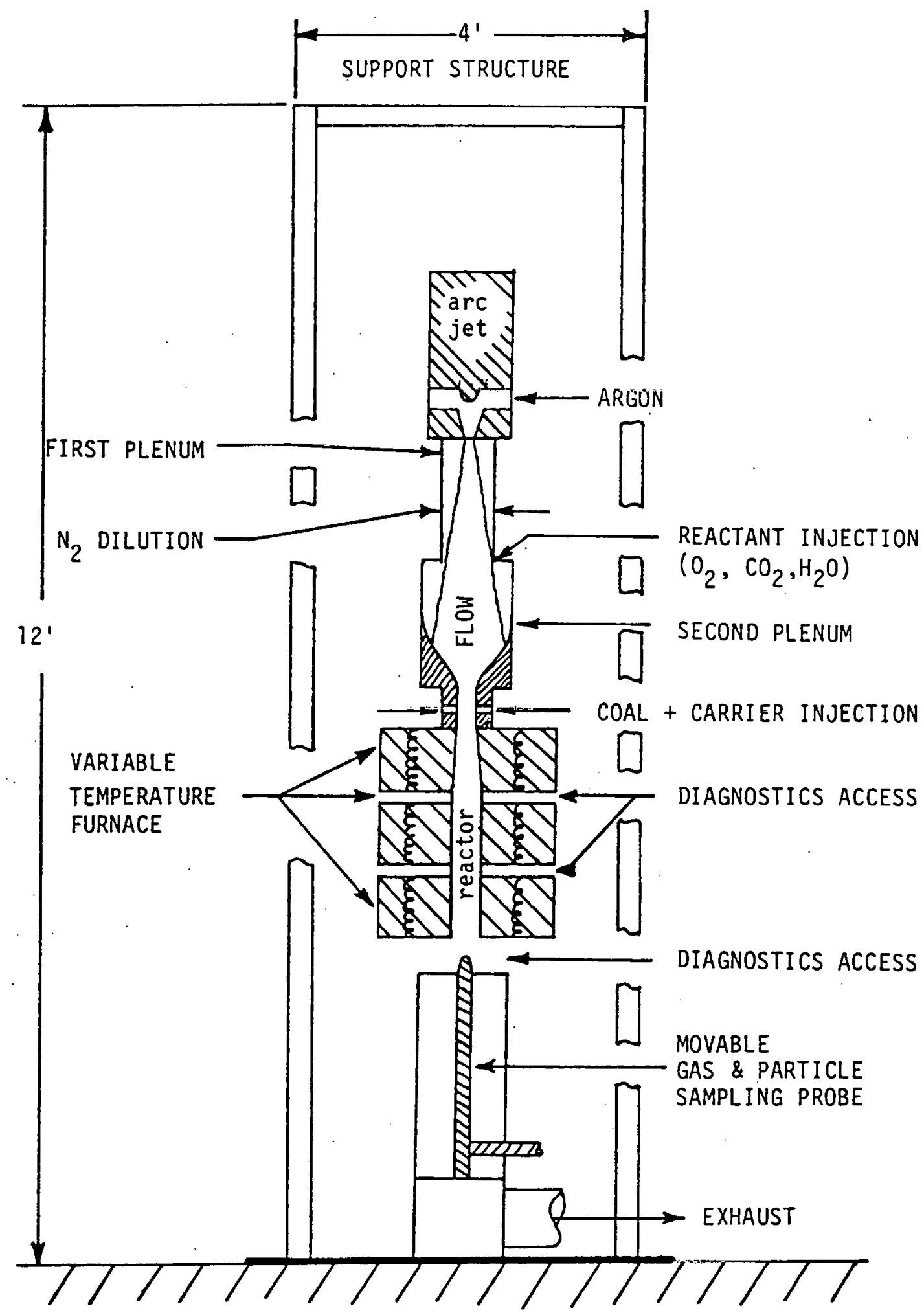

Figure 1. Coal flow reactor. 
Table I. Flow Reactor Characteristics

\begin{tabular}{|c|c|}
\hline $\begin{array}{c}\text { Reactor Internal } \\
\text { Dimensions }\end{array}$ & $\begin{array}{c}9 \text { and } 12 \mathrm{~cm} \text { diameters, } \\
\text { with lengths of 25, 50,75 cm }\end{array}$ \\
\hline Flow Velocity Range & $1.4-25 \mathrm{~m} / \mathrm{sec}$ \\
\hline Residence Times & $3-300 \mathrm{msec}$ \\
\hline Reynolds Number & $1000-6000$ \\
\hline Temperature Range & $1300-2000 \mathrm{~K}$ \\
\hline Reactor Temperature & $(\Delta \mathrm{T} / \mathrm{T})_{\max }=.02$ \\
\hline Uniformity & $\begin{array}{c}\text { Pulverized Coal }-20 \text { to } 100 \mu \mathrm{m} \mathrm{dia} \\
\text { Gas Phase Reactants }-\mathrm{O}_{2}, \mathrm{CO}_{2}, \mathrm{H}_{2} \mathrm{O}\end{array}$ \\
\hline
\end{tabular}

6. At the exit of the flow reactor, an exhaust section is provided for water cooling the hot gas effluent. Also located in this section is a traversing sampling probe used for acquiring both gas and particulate samples. The sample probe can be axially positioned anywhere from the reactor exit to the diffuser entrance thereby obtaining gas $\left(\mathrm{CO}_{2}, \mathrm{CO}, \mathrm{O}_{2}\right)$ and particle data as a function of residence time (distance) in the reactor.

The final design and specification of dimensions was predicated on minimizing heat loss and particle deposition on the reactor walls subject to achievement of the required residence times and flow uniformity. The results of these tradeoffs is a reactor design with the following features:

- Uniform flow is obtained in the central core region of the reactor tube, which allows for accurate centerline probing as well as line-of-sight optical measurements at the access ports and reactor exit. We have obtained experimental temperature, gas composition, velocity, and particle size and number density measurements which confirm that all these properties are uniform across the reactor duct except for a relatively thin boundary layer $(\sim 1 \mathrm{~cm})$ near the reactor wall. Representative results are shown in Figs. 2 and 3.

- Axial temperature drops in the flow reactor are $\leq 2 \%$ in the worst case, providing nearly isothermal reaction conditions. 


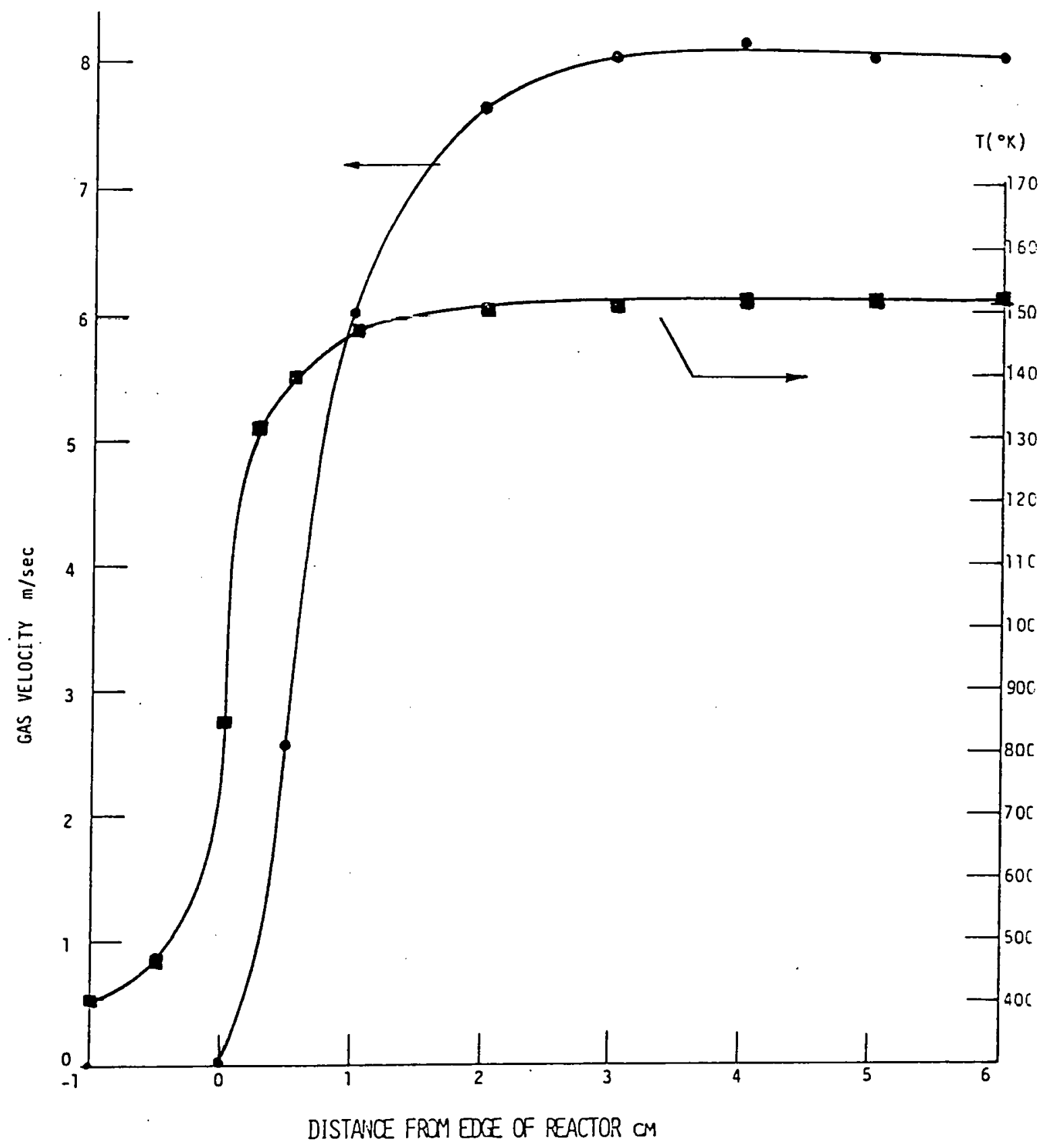

Figure 2. Radial exit velocity and temperature profile. 


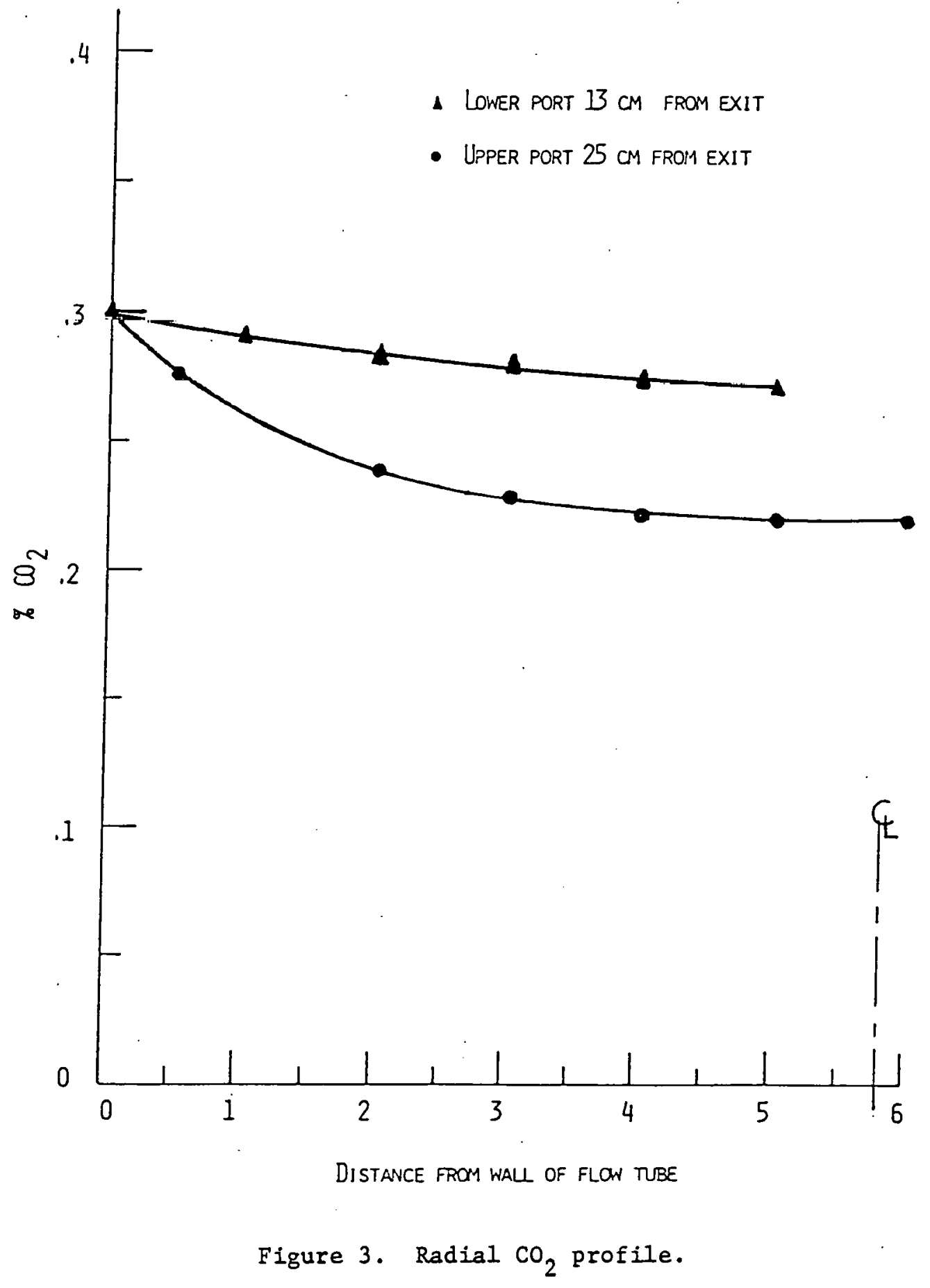


A coreless-screw coal feeder has been designed and fabricated at Stanford and provides a uniform feedrate to within $\pm 3 \%$. The coal/gas mixture is carried to the reactor in two $0.25 \mathrm{~cm}$ diameter tubes, where the two coal/gas streams are injected perpendicularly to the main argon $/ \mathrm{O}_{2} / \mathrm{N}_{2}$ flow and $180^{\circ}$ to each other to minimize coal impingement on the throat walls. Particle heating rates are in the range $10^{5}-10^{60}$ $\mathrm{K} / \mathrm{sec}$. Thermal tests have shown that the reactor has an operating temperature range up to $2100^{\circ} \mathrm{K}$ at mass flows up to $40 \mathrm{gm} / \mathrm{sec}$, with the temperature easily controlled by adjusting the arc jet current and $\mathrm{N}_{2}$ dilution flowrate.

Diagnostics. An essential element of this flow reactor facility is the set of diagnostics used to acquire the data. Table II lists the required measurements and techniques to be used in data acquisition. Gas samples are withdrawn through the traversing water cooled probe, quenching the reactants. Measurement of product species $\left(\mathrm{CO}, \mathrm{CO}_{2}\right)$ and the particle feed rate determines the extent of reaction as a function of rasidence time (distance) within the reactor. It should be noted that the reactivity measurement is obtained from the particle and gas flow in the uniform central core of the reactor, rather than being averaged over the entire cross section.

Optical configurations have been designed and fabricated (Fig. 4) to provide the capability for sodium line-reversal, in-situ particle sizing and transit timing diagnostics. Thus, measurements of gas temperature, particle temperature, particle size and average particle velocity are available.

The theory and measurement applications of the laser in-situ particle size measurement are described in References $[2,3,4]$. This technique has demonstrated capabilities for in-situ measurements of the size distribution of spherical, light absorbing, and irregular-shaped particles in the size range 2-80 $\mathrm{mm}$, at number densities up to $\sim 10^{5} / \mathrm{cm}^{3}$ for the smallest particles. 


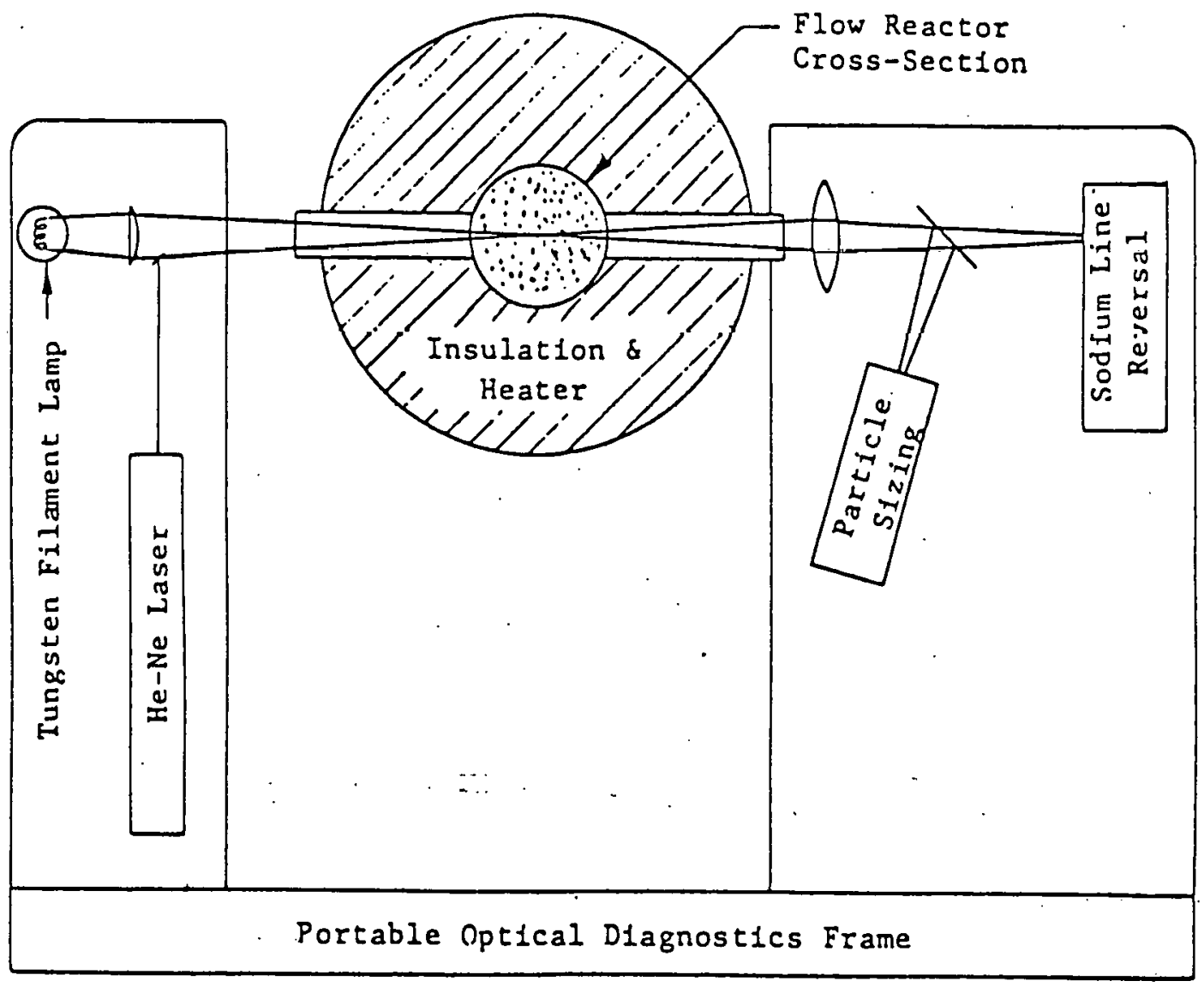

Figure 4. Plan view of flow reactor diagnostics. 
Table II. Diagnostics

\begin{tabular}{|c|c|}
\hline Gas Sampling of Products & $\begin{array}{c}\mathrm{CO}, \mathrm{CO}_{2}, \mathrm{O}_{2}, \mathrm{H}_{2} \mathrm{O} \\
\text { NDIR Spectroscopy } \\
\text { Electrochemical Analyzer }\end{array}$ \\
\hline Gas \& Particle Temperatures & $\begin{array}{c}\text { Sodium Line-Reversal } \\
\text { Traversing Thermocouple } \\
\text { Two-Wavelength Pyrometry }\end{array}$ \\
\hline Particle Characterization & $\begin{array}{c}\text { Laser In-Situ Optical Sizing; } \\
\text { Structure from Probe Collection Sample } \\
\text { Flow Veloctty and }\end{array}$ \\
\end{tabular}

Results of particle size measurements are given in Fig. 5, showing cumulative number density distributions which compare partial and complete coal particle burnout results under combustion conditions with the input coal size distribution under ambient flow conditione. The total mass "at complete burnout should correspond to the amount of inert material in the coal $(s 6 \%$ ), and taking the average ash density to be 3.2 $\mathrm{gm} / \mathrm{cm}^{3}$ based on an ash analysis, an ash mass fraction of $\sim 7 \%$ is obtained. A mass balance under ambient conditions also gives excellent agreement (within 10\%) with an independent collection measurement of the coal particle mass. The particle size measurement will continue to serve as a powerful technique for studying the physical behavior of pulverized coal behavior under various combustion conditions. In conjunction with the particle size measurements, the local velocity can also be measured by means of a beam transit timing technique [5], which gives an important check on the particle residence time.

As shown in Fig. 4, we can use the same optical line-of-sight as for the particle size measurement to obtain Na-line reversal measurements of the gas phase temperature. Having compared Na-line reversal and thermocouple measurements of gas temperature, we are at present using the thermocouple technique to set the gas temperature for routine 


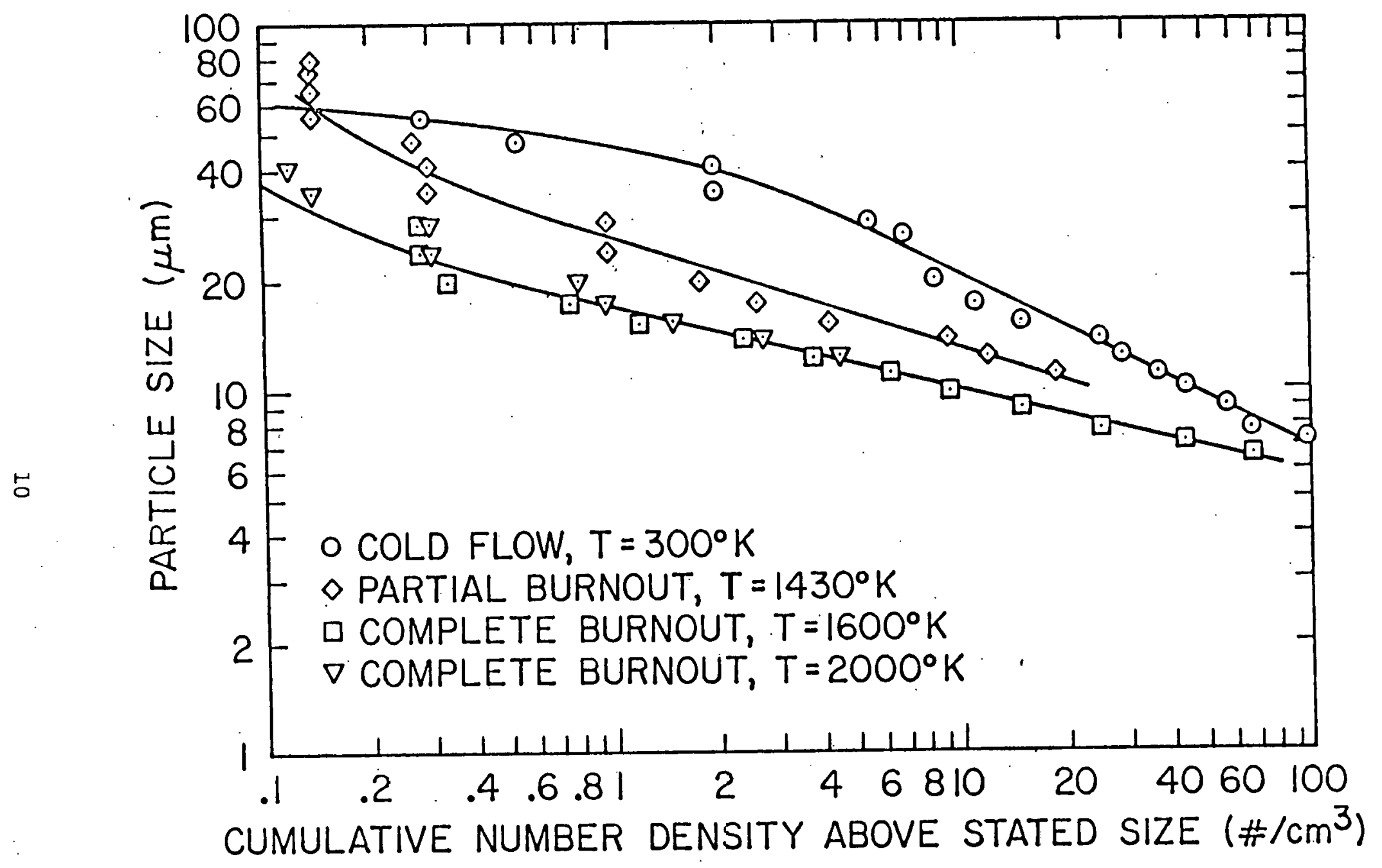

Figure 5. In-situ number density distributions for pulverized coal at four reaction temperatures. 
data collection. The remaining optical technique is a two-color pyrometer modified for fast time response to measure particle temperatures. Coupled with the optical techniques are equally important traversing thermocouple gas temperature measurements and probe sample measurements of combustion products $\left(\mathrm{CO}, \mathrm{CO}_{2}, \mathrm{O}_{2}\right)$. The improved axially traversing probe shown in Fig. 1 is simultaneously used for collection of gas and partially reacted coal samples which are analyzed for size and porosity characteristics. In addition, a pitot probe is used to obtain velocity profiles across the reactor (Fig. 2). 


\subsection{EXPERIMENTS WITH MONTANA ROSEBUD COAL}

Initial experiments with Montana Rosebud coal have been performed in the Stanford flow-tube reactor. Reactivity data were collected for two size ranges under oxidizing conditions and for gas temperatures between $1040 \mathrm{~K}$ and $1750 \mathrm{~K}$. The following section describes coal characterization, experimental conditions and results for the two size ranges. A discussion of the results concludes this section.

Coal Characterization. Both'proximate and ultimate analyses have been made on the Montana Rosebud coal. The proximate analysis gives the weight percent of moisture, ash volatile matter and fixed carbon as well as the heating value. The ultimate analysis gives the elemental composition of the coal excluding moisture and ash. Figure 6 reproduces the proximate and ultimate analyses for the 44-74 $\mu \mathrm{m}$ size coal. Within the rank system for coals, Montana Rosebud is a high-volatile bituminous coal [6].

Size measurements of the coal have been made using SEM (scanning electron microscopy), optical microscopy and in situ particle sizing $[2,3]$, a nonintrusive optical method. Figure 7 shows the raw 44-74 $\mu \mathrm{m}$ coal magnified 100 times and one particle magnified 1000 times. The raw coal shows sharp edges and planar faces as well as a variety of shapes. Size and mass distributions of the raw 44-74 $\mu \mathrm{m}$ coal are shown in Figs. 8 and 9. The size distribution was determined using an optical microscope. The mass distribution was generated by a diameter-cube weighting of the size distribution and then normalizing to the mass of a $44 \mu \mathrm{m}$ particle. Although the size distribution peaks noticeably at $44 \mu \mathrm{m}$ the mass distribution is much more uniform particularly between 55 and 77 um. To faciliate comparison of size data taken with the in-situ particle sizer and optical microscope, plots of particle size versus cumulative mass have been made. This comparison is shown in Fig. 10. Both sets of data are for the 44-74 $\mu \mathrm{m}$ coal; agreement is good. 
COMPOSITION OF $44-74 \mu \mathrm{m}$

MONTANA ROSEBUD COAL

PROXIMATE ANALYSIS

\begin{tabular}{rr} 
\% Moisture & 6.05 \\
\% Ash & 13.54 \\
\% Volatile & 36.57 \\
\% Fixed Carbon & 43.84 \\
\hline & 100.00 \\
Btu/lb. & 10032 \\
\% Sulfur & 0.94
\end{tabular}

ULTIMATE ANALYSIS

\begin{tabular}{rr} 
\% Moisture & 6.05 \\
\% Carbon & 59.68 \\
\% Hydrogen & 3.79 \\
\% Nitrogen & 0.79 \\
\% Chlorine & 0.04 \\
\% Sulfur & 0.94 \\
\% Ash & 13.54 \\
\% Oxygen (diff.) & 15.17 \\
\hline
\end{tabular}

Figure 6. 


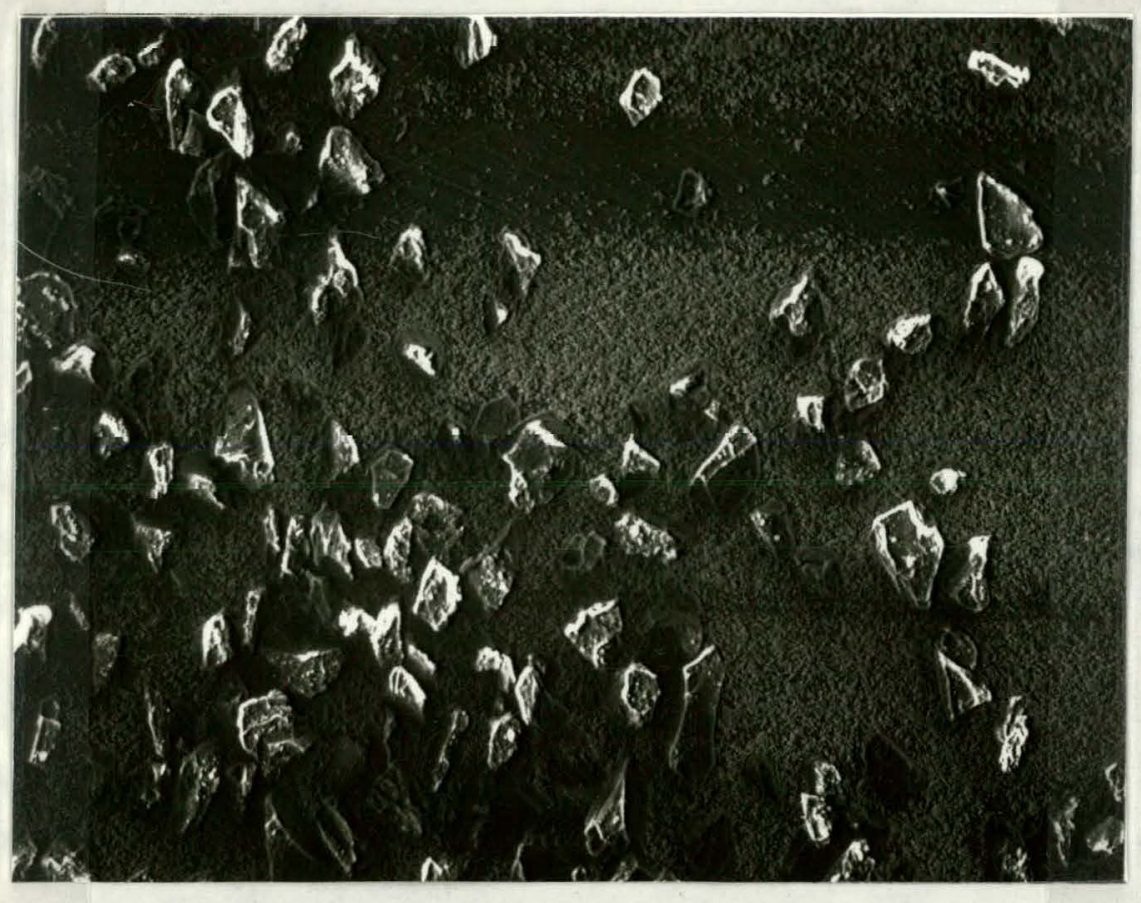

$100 \mathrm{x}$

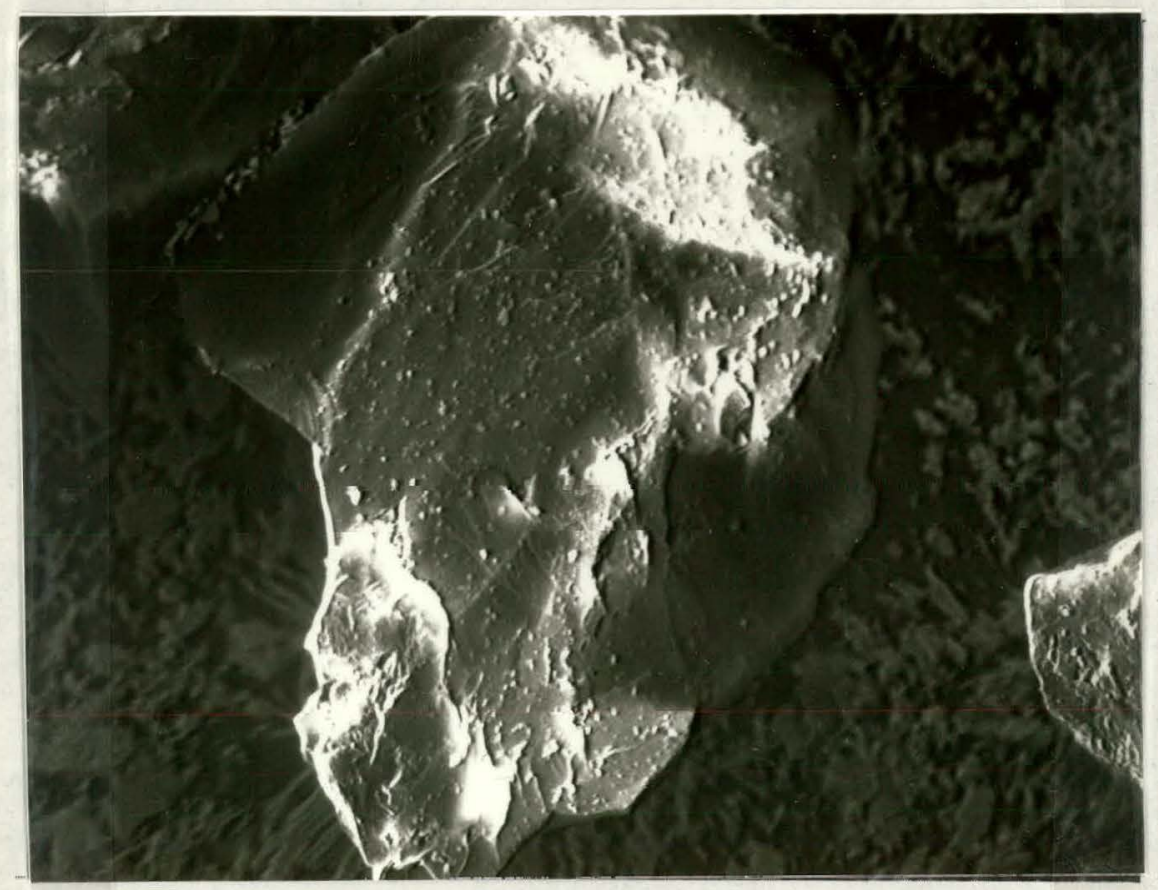

$1000 \mathrm{X}$

Figure 7. 
SIZE DISTRIBUTION FOR $44-74 \mu \mathrm{m}$

MONTANA ROSEBUD

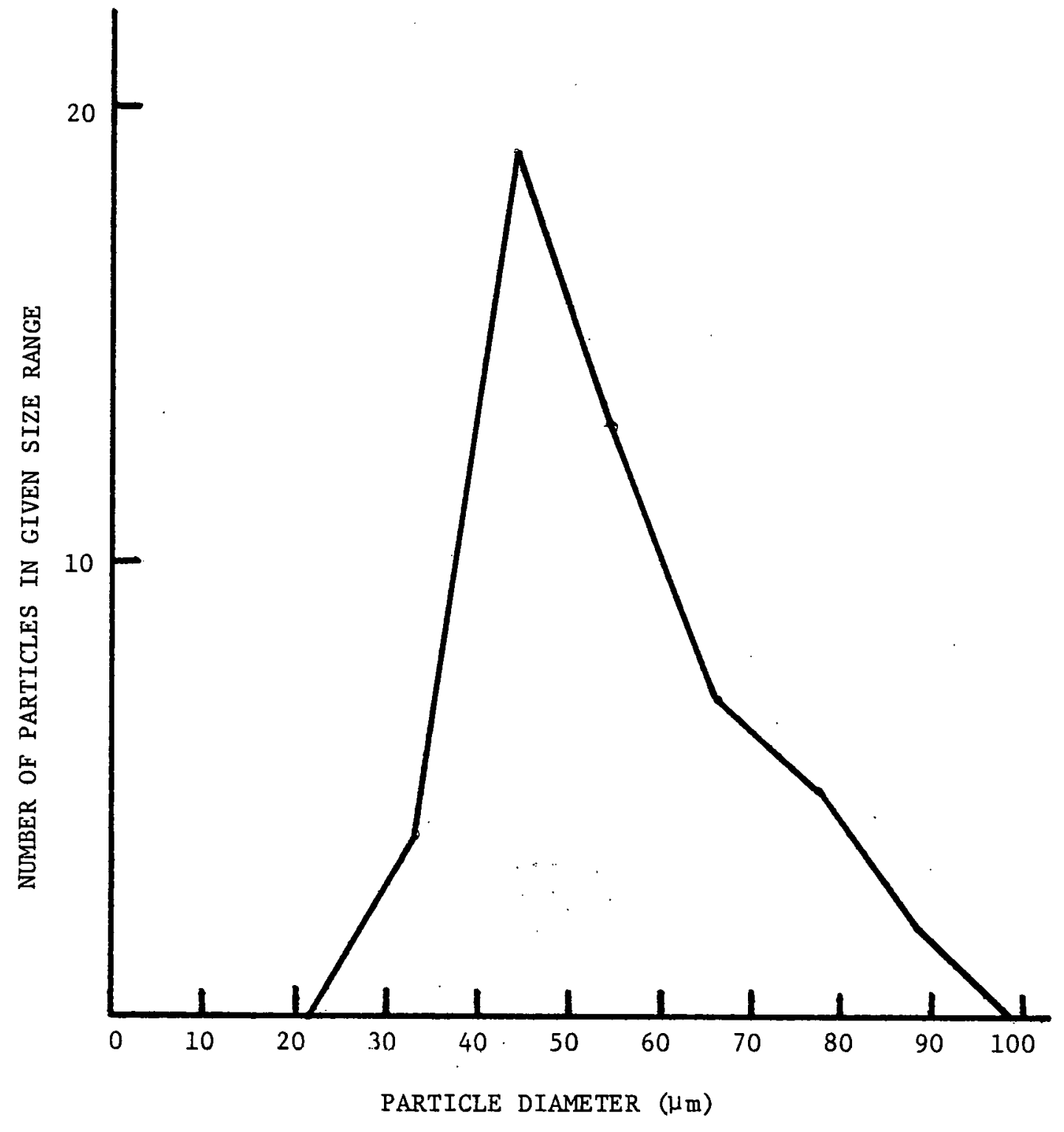

Figure 8. 
MASS DISTRIBUTION FOR $44-74 \mu \mathrm{m}$

MONTANA ROSEBUD

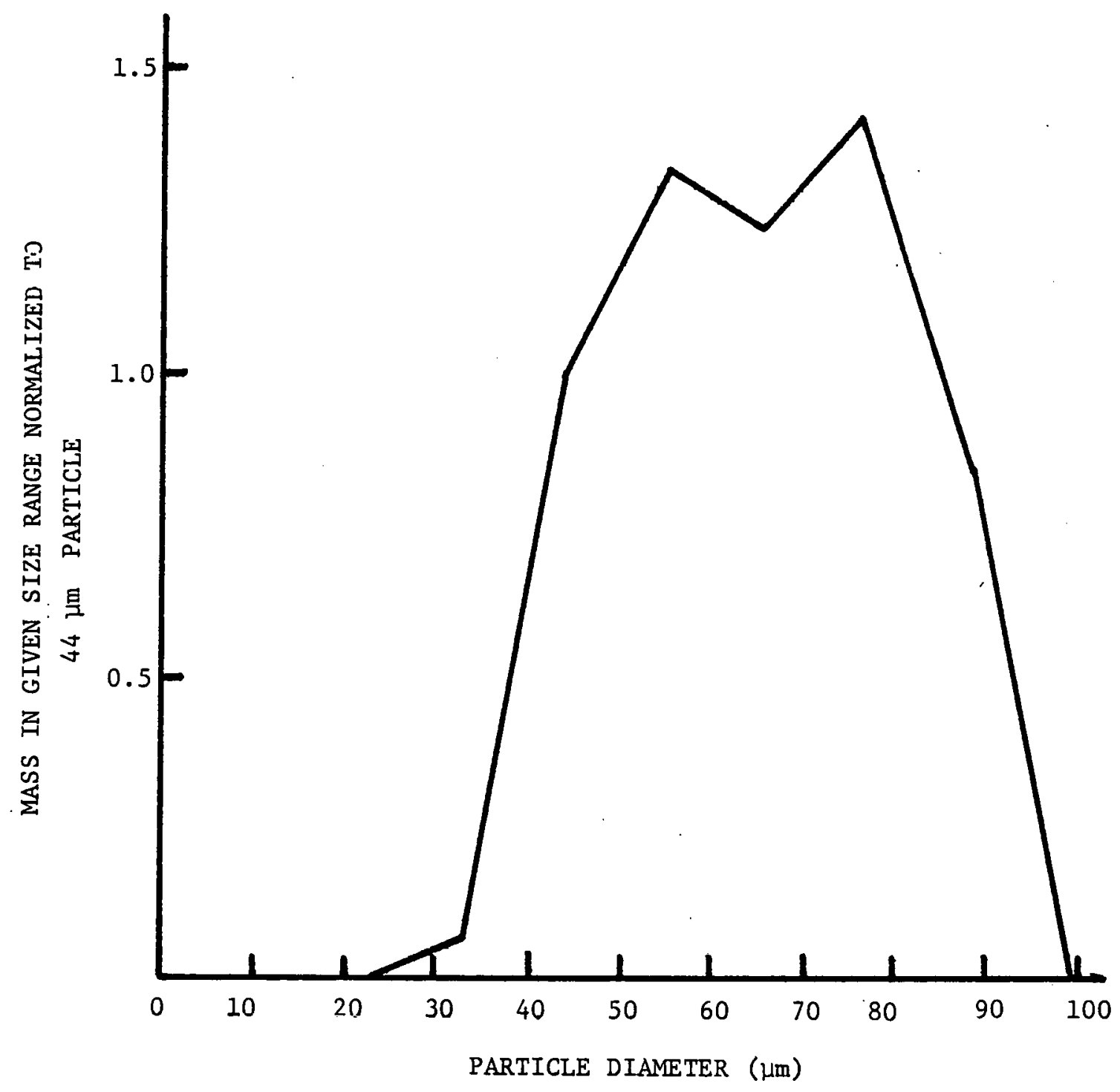

Figure 9. 
COMPARISON OF IN-SITU \& OPTICAL MICROSCOPY MASS

DETERMINATION FOR $44-74 \mu \mathrm{m}$ COAL

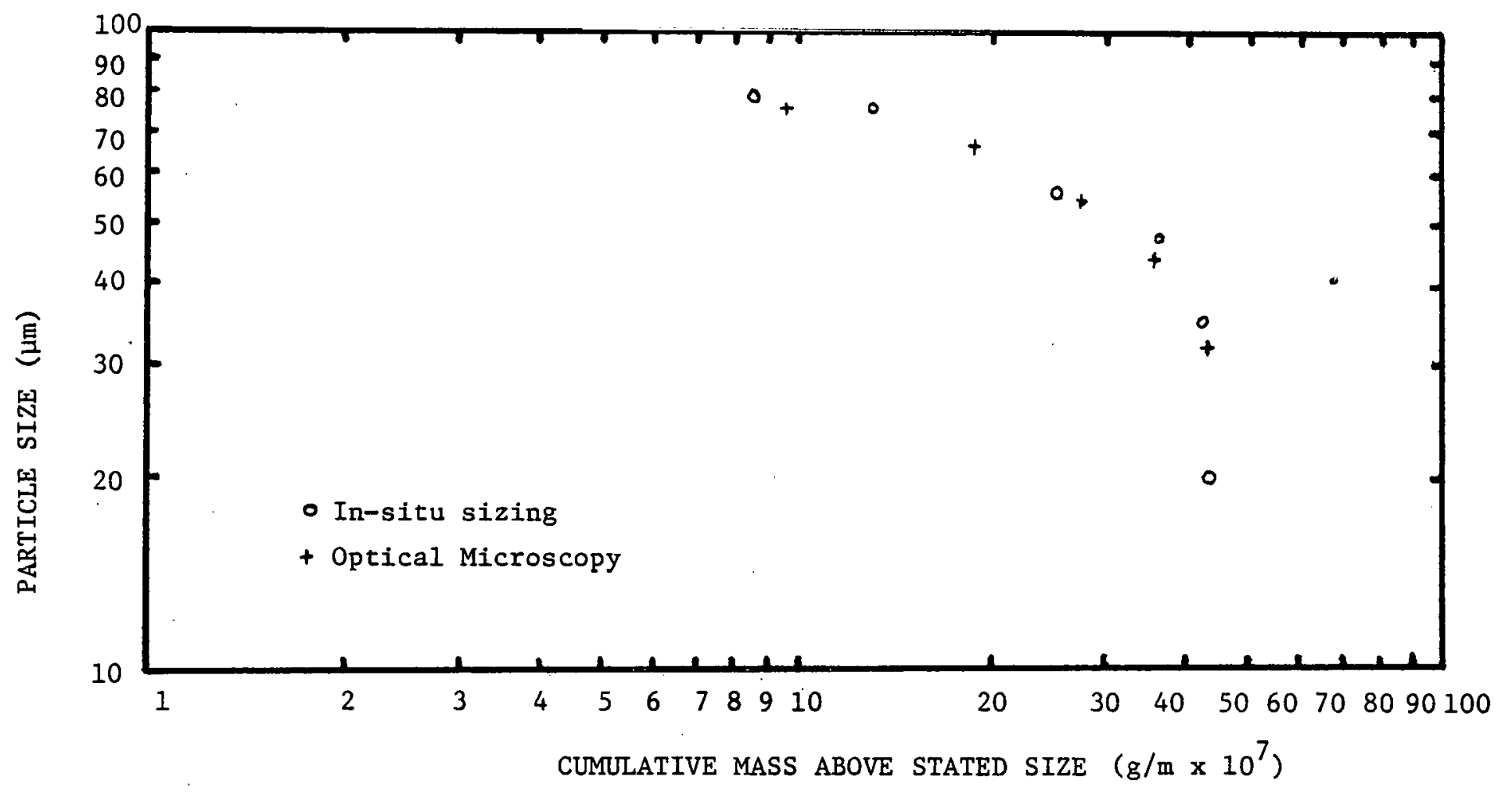

Figure 10. 
Experimental Conditions. Beginning in October of 1980 three separate experiments were carried out on the Montana Rosebud coal. The first two experiments were done on the 44-74 $\mu \mathrm{m}$ size coal; the last experiment involved the 30-44 $\mathrm{m}$ size. For each test, $0.36 \mathrm{gram}-$ moles/sec of argon was electrically heated to high temperature and subsequently diluted with $0.24 \mathrm{gram}-\mathrm{moles} / \mathrm{sec}$ of room temperature nitrogen. At the entrance of the large plenum, as shown in Fig. 1, oxygen was added in appropriate amounts to give the desired concentration. The pulverized coal in an argon carrier was injected at the throat of the contraction-expansion section. The wall temperature of the flow tube was typically between $1000 \mathrm{~K}$ and $1300 \mathrm{~K}$ depending somewhat on location, gas temperature and time into the experiment.

Experiment No. 1 involved the 44-74 $\mu \mathrm{m}$ coal burning in the presence of $7.3 \%$ oxygen. The coal mass feed rate was 2.85 grams/min. This low coal feed rate accounts for only $0.2 \%$ of the total mass throughput and did not affect the oxygen concentration significntly. The heating value of the coal was only $5 \%$ of the enthalpy of the hot gases. The enthalpy input from the coal could raise the gas temperature by no more than $70 \mathrm{~K}$ but actually offset in part the heat loss along the flow-tube which was of the same order. The gas temperatures for this experiment were varfed between $1610 \mathrm{~K}$ and $1750 \mathrm{~K}$.

Experiment No. 2 had the same conditions as experiment No. 1 except that the gas temperatures were lower: between $1040 \mathrm{~K}$ and $1140 \mathrm{~K}$.

Experiment No. 3 was carried out using the smaller coal size: 30-44 $\mathrm{m}$. The amount of oxygen used was $7.3 \%$ and gas temperatures were varied between $1215 \mathrm{~K}$ and $1580 \mathrm{~K}$. As in the first two experiments the reactor wall temperature was around $1100 \mathrm{~K}$. During this third experiment an additional parameter was investigated: the amount of argon carrier used to inject the raw coal. The amount of carrier used turned out to be important. Further discussion of this aspect of the experiment will be given later on in the report. 
Measurements with 44-74 $\mu \mathrm{m}$ Coal. Data taken with the 44-74 $\mu \mathrm{m}$ Montana Rosebud coal during experiments No. 1 and 2 are shown in Fig. 11. The ordinate is percent carbon conversion ( to $\mathrm{CO}_{2}$ ) based on the ultimate analysis and coal mass feed rate; the abscissa is the particle residence time $\tau$ based on 'plug flow' considerations. Associated with each curve is an average gas temperature taken near the exit of the flow reactor. Oxygen was $7.3 \%$ of the total gas flow rate for each curve shown. For each case shown in Fig. 11, Table III lists gas temperature, particle temperature, mass reactivity based on external surface area and the ratio of this reactivity to the diffusion limited reactivity as determined from calculation. The values given are based on data taken at approximately $\tau=50 \mathrm{msec}$. It should be noted that the diffusion limited reactivity determines the maximum rate of carbon evolution possible at normal combustion temperatures in the char burnout regime.

For the case where $\mathrm{T}_{\text {gas }}=1140 \mathrm{~K}$ (first item in Table III), radial profiles of $\% \mathrm{CO}_{2}$ as well as radial and axial temperature profiles were taken. Those profiles are shown in Figs. 12 and 13. The \% $\mathrm{CO}_{2}$ profiles show that for the center one-half of the reactor the $\mathrm{CO}_{2}$ concentration was uniform. The rise near the reactor walls was due in part to more extensive burnout, a result of longer residence times caused by a decrease in velocity in the boundary layer. The temperature profiles show a high degree of uniformity over the areas of interest. Although the axial temperature dropped through the diffuser (50 to 34 $\mathrm{cm})$, 1ittle decrease was observed in that portion of the reactor where char reactivity data was determined.

Measurements with 30-44 $\mu \mathrm{m} \mathrm{Coal}$. Experiment No. 3 used the smaller 30-44 Montana Rosebud and those data are shown in Fig. 14. As was the case for the first two experiments the oxygen was $7.3 \%$ of the total gas flow. Data similar to that given in Table III for the 44-74 $\mu \mathrm{m}$ coal are given in Table IV for the 30-44 $\mu \mathrm{m}$ coal. The argon carrier gas used to inject the raw coal was varied during experiment No. 3. The results are shown in Fig. 15. The ordinate is percent $\mathrm{CO}_{2}$ at reactor centerline and the abscissa is the amount of argon carrier in liters per minute. 
EXTENT OF CARBON CONVERSION FOR

$44-74 \mu \mathrm{m}$ MONTANA ROSEBUD

$$
\begin{aligned}
& \mathrm{T}_{\text {gas }}=1140 \mathrm{~K} \\
& \text { - } \mathrm{T}_{\text {gas }}=1600 \mathrm{~K} \\
& \text { - } \mathrm{T}_{\text {gas }}=1750 \mathrm{~K}
\end{aligned}
$$

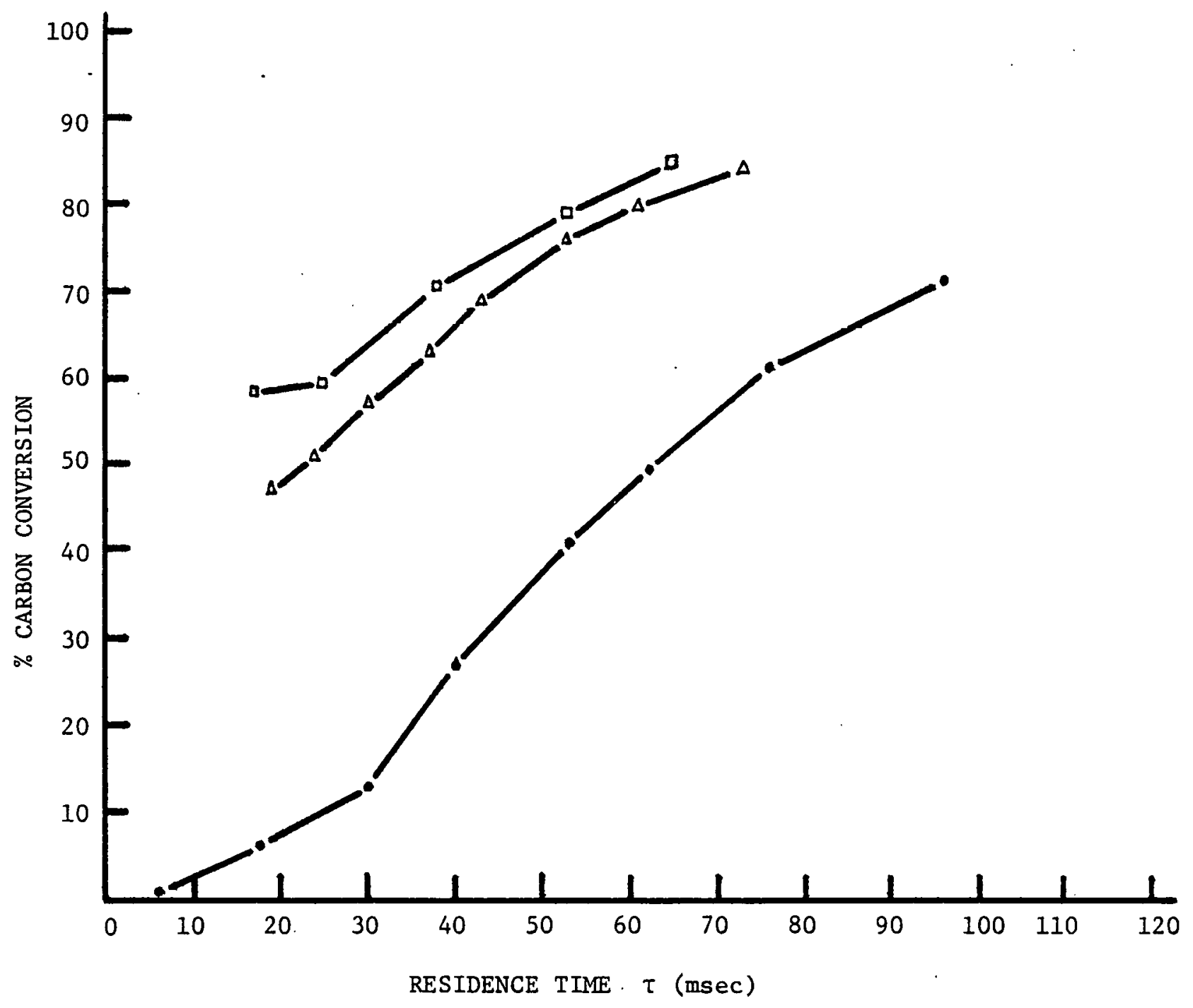

Figure 11. 
TABLE III

RESULTS FROM COMBUSTION EXPERIMENTS WITH

$$
44 \text { - } 74 \text { Im MONTANA ROSEBUD }
$$

\begin{tabular}{lccc}
\hline$T_{\text {gas }}(\mathrm{K})$ & $\mathrm{T}_{\text {Particle }}(\mathrm{K})$ & $\mathrm{R}_{\mathrm{M}}\left(\mathrm{gm} / \mathrm{cm}^{2} \mathrm{sec}\right)$ & $\mathrm{R}_{\mathrm{M}} / \mathrm{R}_{\mathrm{MT}}$ \\
\hline 1140 & 1620 & $1.6 \times 10^{-2}$ & $\sim 1$ \\
1600 & 1880 & $1.9 \times 10^{-2}$ & $\sim 1$ \\
1750, & 2140 & $2.1 \times 10^{-2}$ & $\sim 0.95$ \\
\hline
\end{tabular}


$\% \mathrm{CO}_{2}$ RADIAL PROFILES AT TWO

AXIAL LOCATIONS

- $\tau=37 \mathrm{msec}$ @ $\mathrm{G}$

- $\tau=57 \mathrm{msec} @ q$

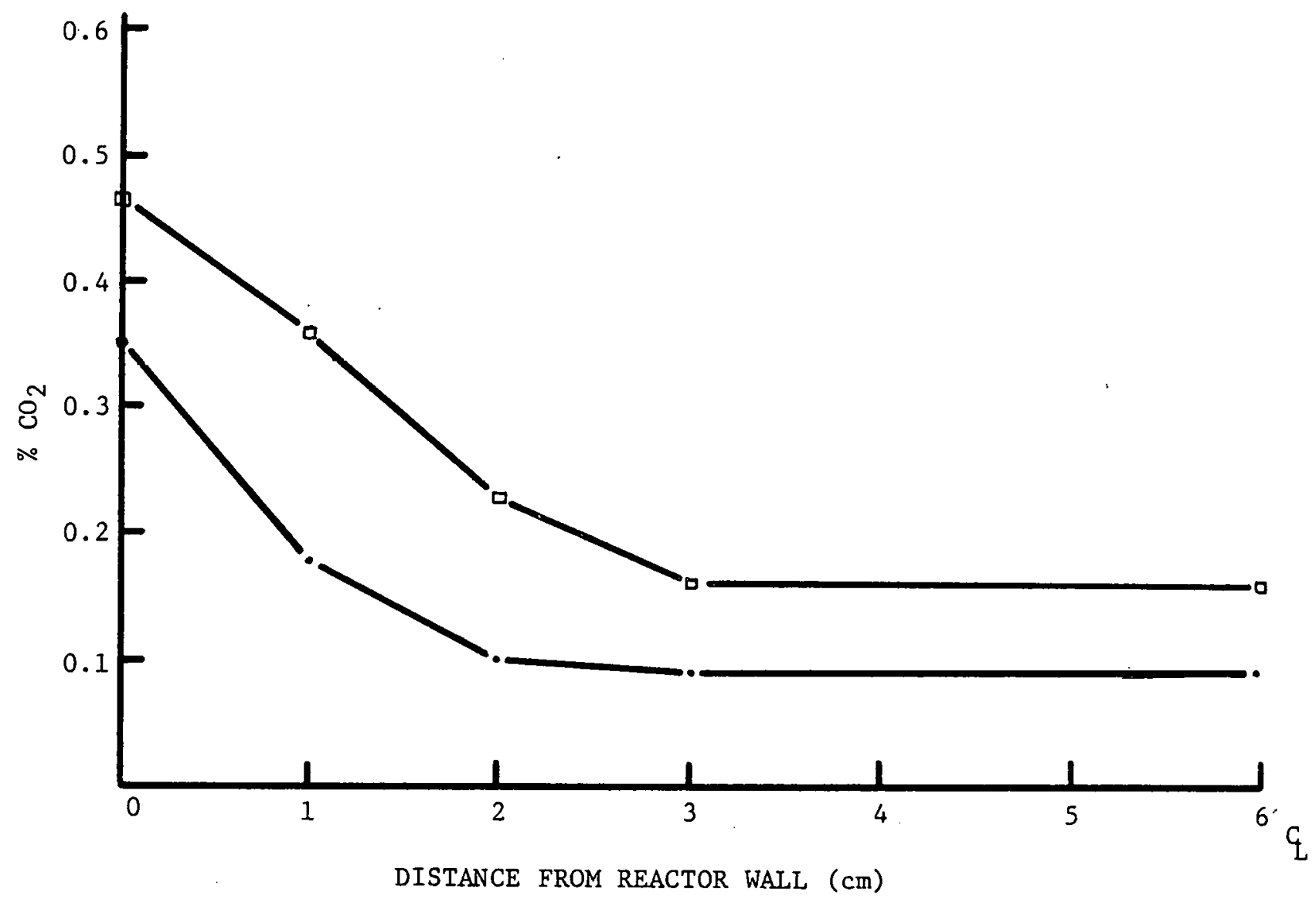

Figure 12 . 


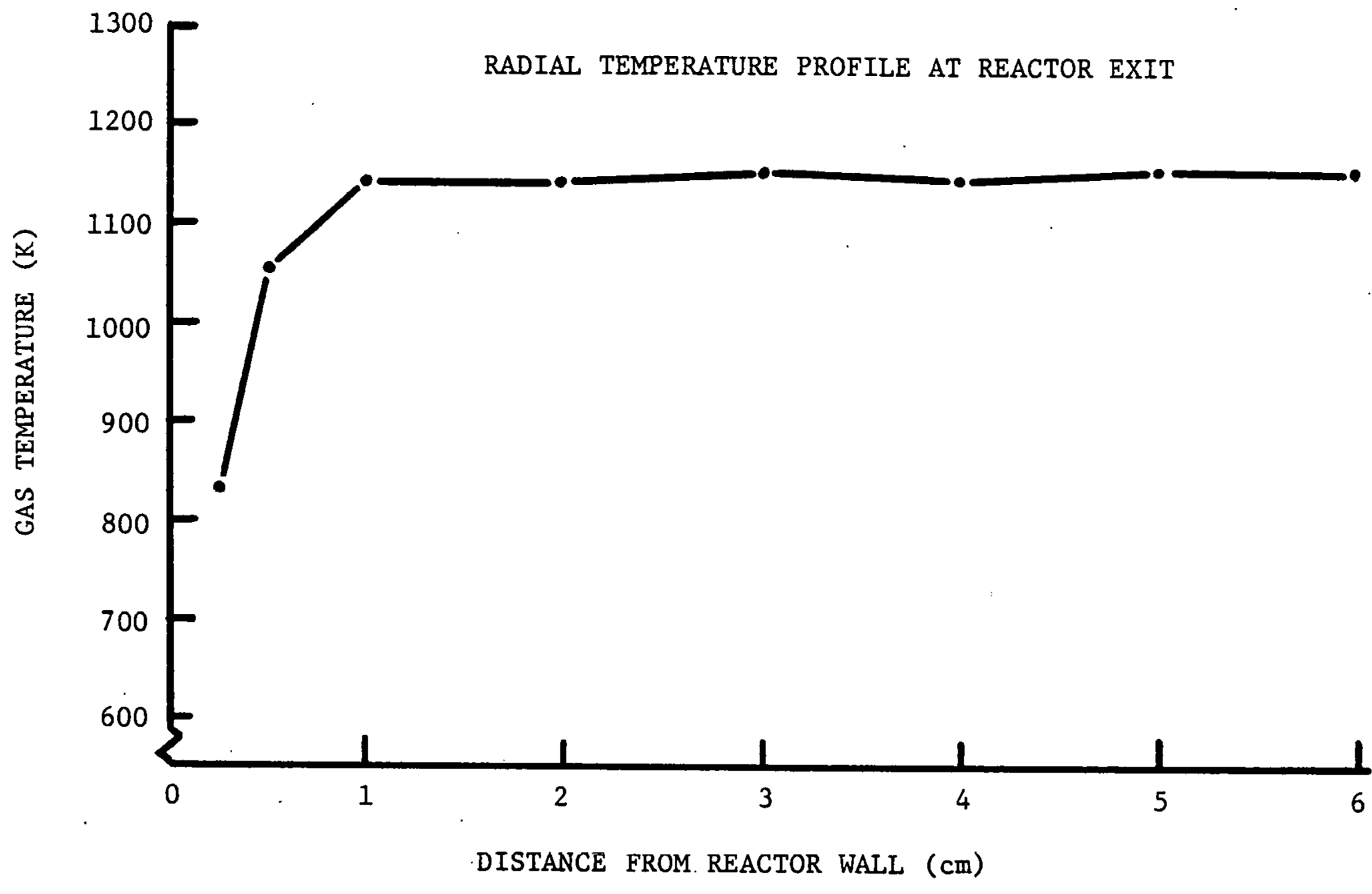

(c)

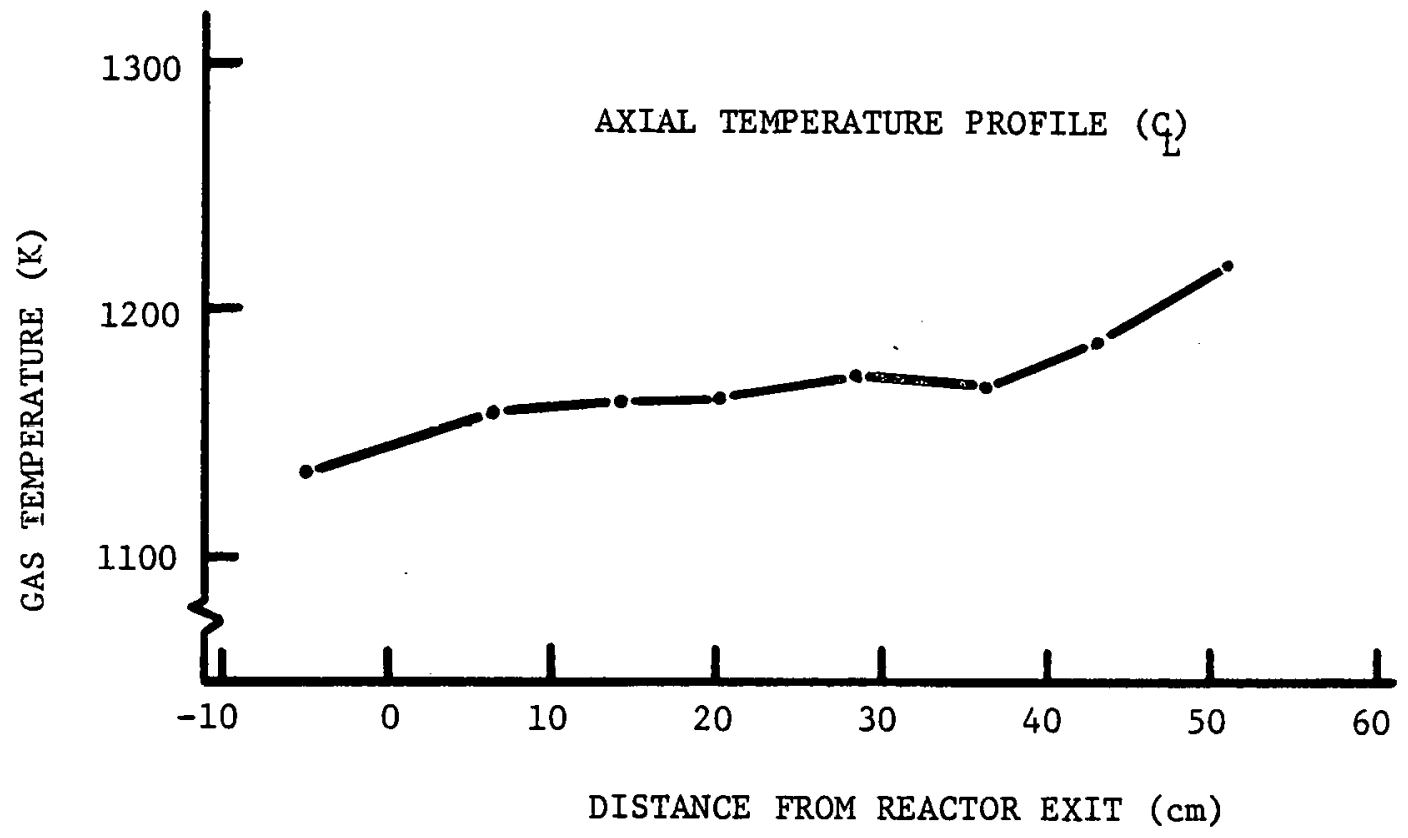

Figure 13. 
EXTENT OF CARBON CONVERSION FOR

$$
30-44 \mu \mathrm{m} \text { MONTANA ROSEBUD }
$$

- $\mathrm{T}_{\text {gas }}=1215 \mathrm{~K}$

$\Delta \mathrm{T}_{\text {gas }}=1580 \mathrm{~K}$

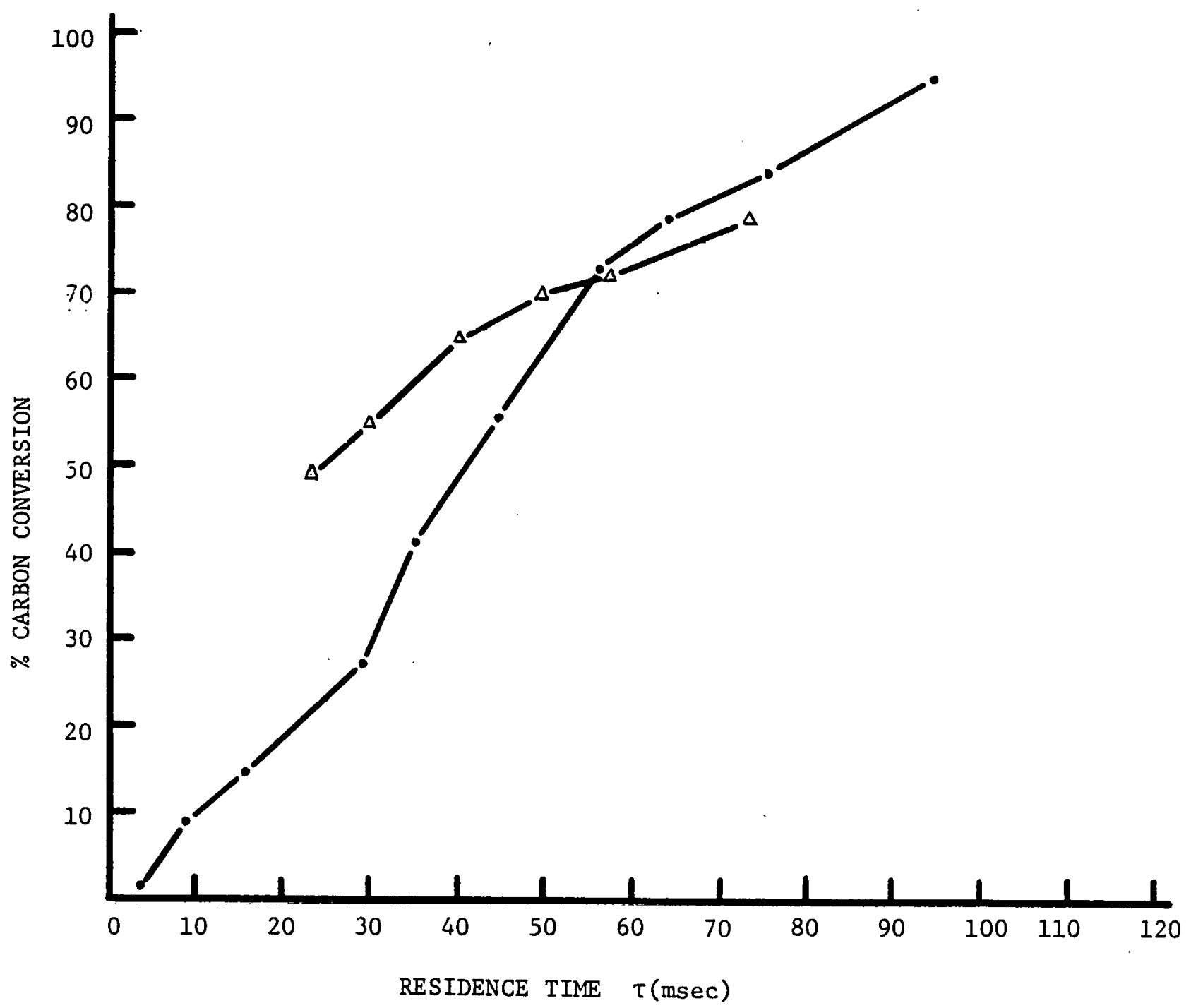

Figure 14 . 
TABLE IV

RESULTS FROM COMBUSTION EXPERIMENTS WITH

$30-44 \mu \mathrm{m}$ MONTANA ROSEBUD

\begin{tabular}{cccc}
\hline $\mathrm{T}_{\text {gas }}(\mathrm{K})$ & $\mathrm{T}_{\text {Particle }}{ }^{(\mathrm{K})}$ & $\mathrm{R}_{\mathrm{M}}$ gm/ $\mathrm{cm}^{2}$ sec & ${ }^{\mathrm{R}}{ }_{\mathrm{M}} / \mathrm{R}_{\mathrm{MT}}$ \\
\hline 1215 & 1835 & $2.1 \times 10^{-2}$ & 0.75 \\
1580 & 1885 & $0.8 \times 10^{-2}$ & 0.3 \\
\hline
\end{tabular}


EFFECT OF ARGON CARRIER ON $\% \mathrm{CO}_{2}$

$$
\begin{array}{r}
-10.2 \mathrm{~cm} \\
0-1.3 \mathrm{~cm} \\
\Delta \quad 12.7 \mathrm{~cm} \\
\text { a } 25.4 \mathrm{~cm}
\end{array}
$$

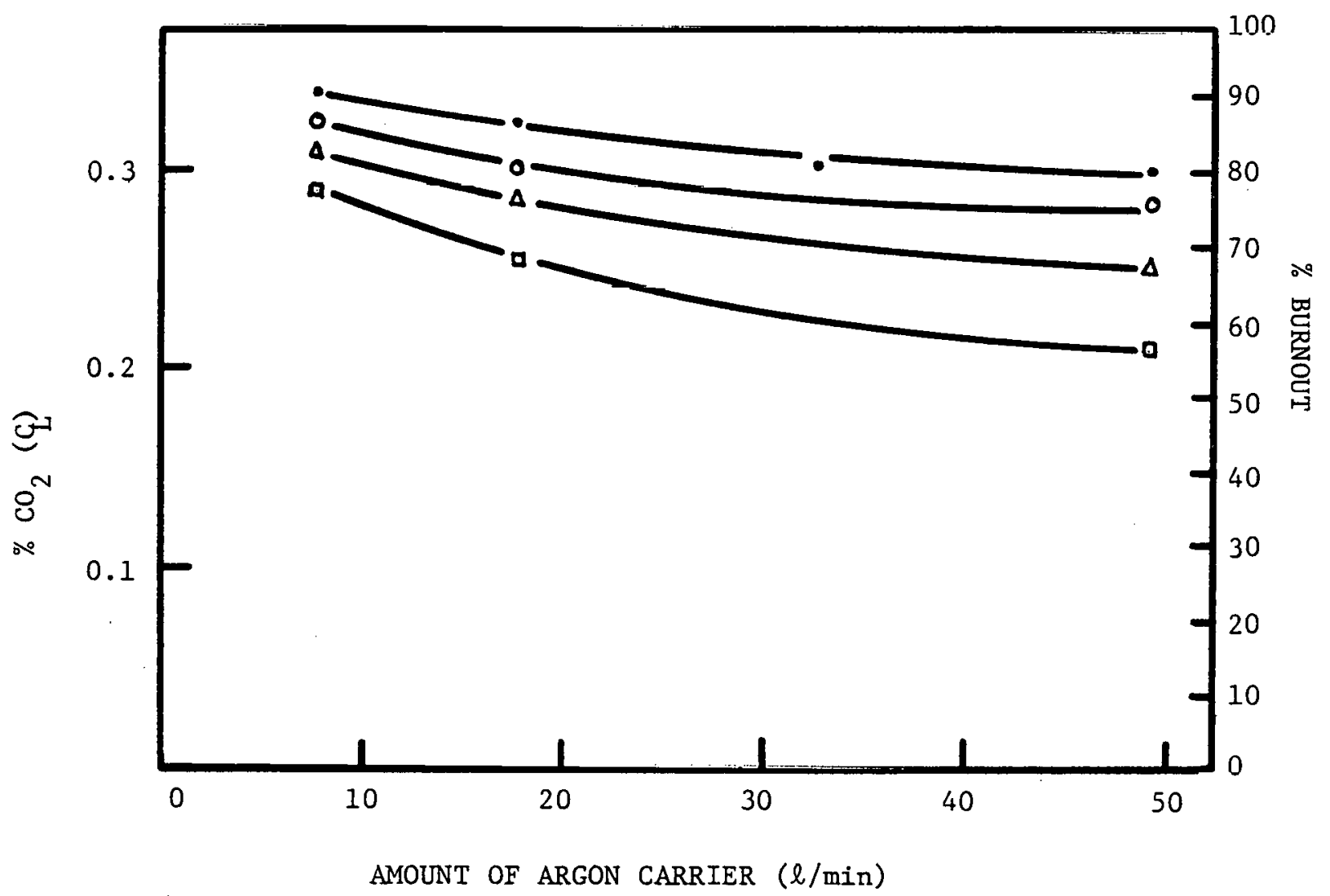

Figure 15. 
The level sets (third variable) are different axial locations in the reactor, measured from the exit. The data points are connected to make the trend more apparent rather than to suggest a quantitative curve fit. In any case at the low end of the scale decreased amounts of carrier gas increase the extent of reaction at a given value of residence time. Changing the amount of carrier gas does not significantly change the residence time because the carrier gas is always a small fraction of the total gas flow ( $<2 \%)$.

Discussion. The experimental results indicate that Montana Rosebud coal has a high mass reactivity with oxygen. Previous evidence of high reactivity for this coal was noted by stickler [7]. The net result of this high reactivity is that combustion rates were, for a number of conditions, diffusion controlled. Work done by Smith [8] and Smith and Tyler [9] on brown coal chars and petroleum coke of similar size show appreciable chemical (kinetic) control. The observation of diffusion limited reactivity applies most evidently to the larger 44-74 $\mu \mathrm{m}$ coal, as would be expected from theory [10]. The smaller 30-44 um coal shows varying degrees of kinetic control, with the second entry in Table IV having a reactivity only $30 \%$ of the diffusion limit.

Two posible explanations are availale for the high reactivity and diffusion control of the larger coal size. First, the intrinsic reactivity of the coal surface is large and/or, second, the internal surface area is large. Since diffusion control existed, little can be said at present about the first possibility. Regarding the second possibility, extensive internal surface area is available even for small depths of oxygen penetration. For example, a spherical $60 \mu \mathrm{m}$ particle has an external surface area of $\sim 1.1 \times 10^{-4} \mathrm{~cm}^{2}$. For highly porous coals, such as Montana Rosebud, specific internal surface areas of $4 \times 10^{6} \mathrm{~cm}^{2} / \mathrm{gm}$ are not uncommon. If oxygen penetrates only $3 \mu \mathrm{m}$ below the surface, the area availale becomes $0.16 \mathrm{~cm}^{2}$. At this point it is difficult to separate pure diffusion control from the case where small but important oxygen penetration has occurred. For a depth of penetration that is a fixed fraction of the diameter, the area avallable for reaction should 
scale as the diameter cubed, or volume of the particle. Some evidence for penetration can be seen in Fig. 16, a SEM micrograph of a partially burned char particle where an extensive macropore structure has been developed.

The experiments carried out on both the 44-74 $\mu \mathrm{m}$ and 30-44 $\mu \mathrm{m}$ coal indicate the importance of initial conditions on both reactivity and extent of burnout at a given time. Two different effects of gas temperature seem to be present. The first involves the amount of volatiles given off early on. As can be seen in Fig. 11, the high gas temperatures promote extensive volatile yield in the first $25 \mathrm{msec}$ or so while lower gas temperatures have no such noticeable effect. It is possible that for the lower temperature case volatiles are being given off but at rates comparable to char oxidation. Work done by Kobayashi [11] lends support to this explanation. The second effect is indicated in Fig. 14. Here the higher gas temperature resulted in much higher carbon conversion at early times, but the net result was lower reactivity and ultimately lower carbon conversion after $\backsim 55 \mathrm{msec}$. One possible explanation is a loss of internal surface arca due to 1039 of micropores [12]. Further experiments and more detailed information on the physical structure of the partially burned coal will be necessary to address this type of behavior. 
PARTIALLY BURNED $77-44 \mu \mathrm{m}$ MONTANA ROSEBUD

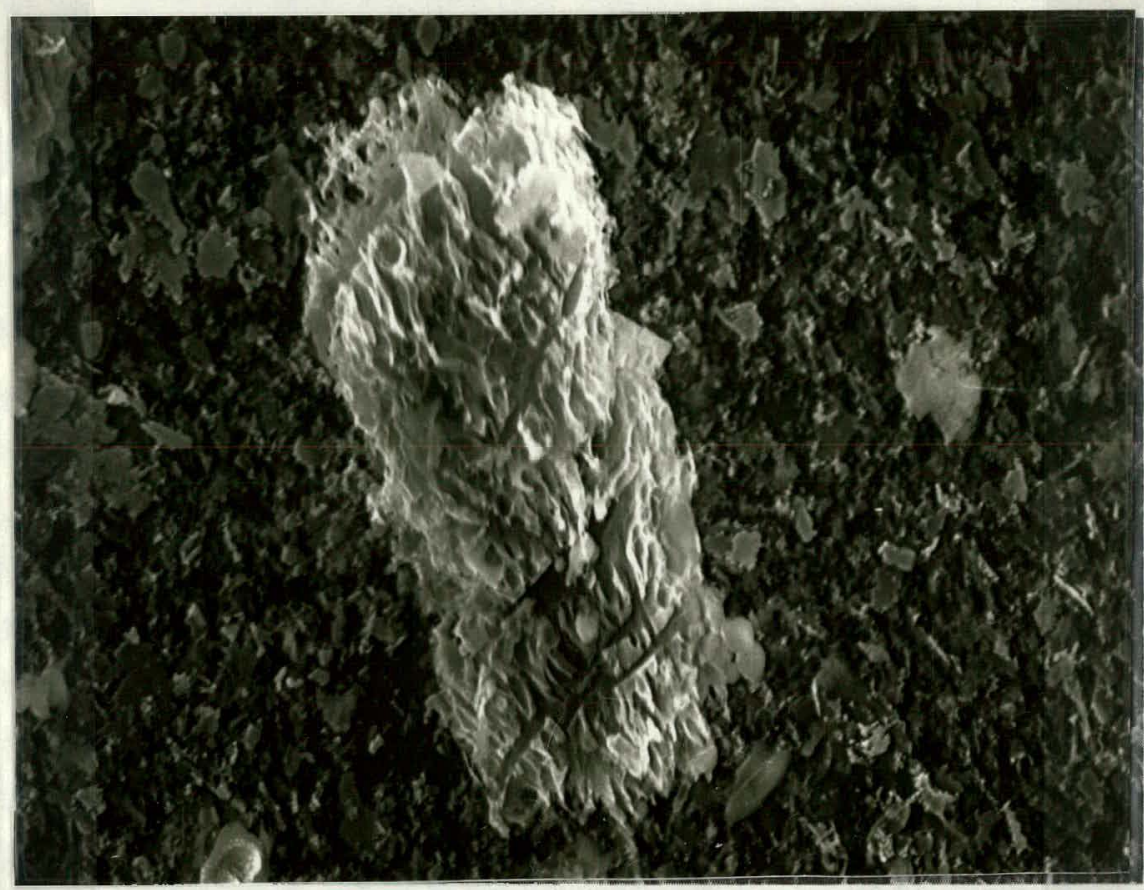

$1000 \mathrm{X}$

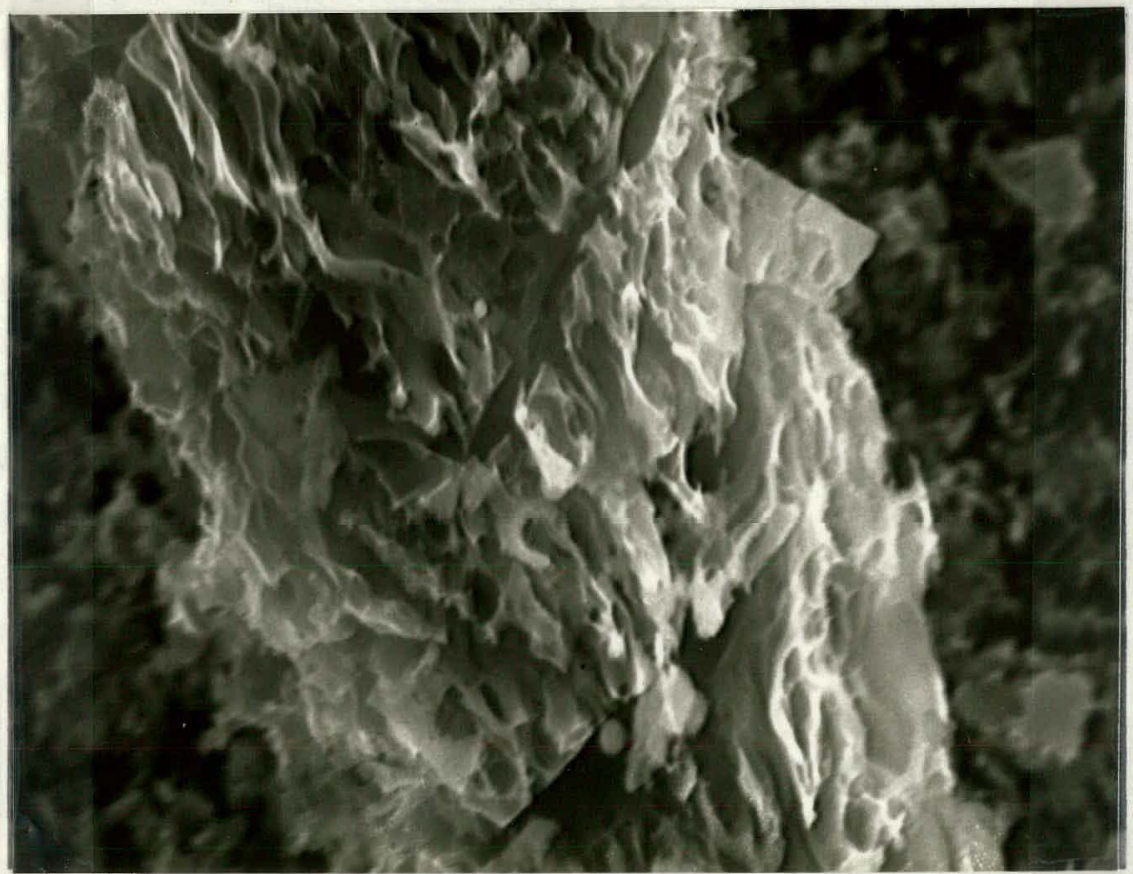

$2000 x$

Figure 16. 


\subsection{REFERENCES}

1. M. Jost, I. Leslie, D. Holve, C. Kruger, "Flow Tube Reactor Study of Pulverized Coal Combustion," presented at Western States Section of the Combustion Institute, BYU, Provo, Utah, April, 1979.

2. D. Holve and S. Self, "Optical Particle Sizing for In Situ Measur $\in$ ments, Part I," J. Appl. Opt., Vol. 18, No. 10, 15 May 1979.

3. D. Holve and S. Self, "Optical Particle Sizing for In Situ Measurements, Part II," J. Appl. Opt., Vo1. 18, No. 10, 15 May 1979.

4. D. Holve, "An In Situ Optical Particle Sizing Technique," presented at the 18th AIAA Aerospare. Sciences Meeting, January 14-16, 1980, Pasadena, California, Paper AIAA-80-0020.

5. D. Hirleman, "Laser Technique for Simultaneous Particle-Size and Velocity Measurements," Optics Letters, Vol. 3, No. 1, July 19.78.

6. W. H. Ode, Coal, Standard Handbook for Mechanical Engineering, 7th edition.

7. D. B. Stickler and S. K. Ubhayakar, "Mechanistic Modeling of Pulverized Coal Combustion," 17th Symposium on Engineering Aspects of Magnetohydrodynamics.

8. I. W. Smith, "Kinetics of Combustion of Size-Graded Pulverized Fuels in the Temperature Range $1200-2700^{\circ} \mathrm{K}$,"Comb. and Flame, Vo1. 17, pp. 303-314 (1971).

9. I. W. Smith and R. J. Tyler, "The Reactivity of a Porous Brown Char to Oxygen between 630 and $1812^{\circ} \mathrm{K}, "$ Comb. Sci. and Tech., Vol. 9, pp. 87-94 (1974).

10. M. F. R. Mulcahy and I. W. Smith, "Kinetics of Combustion of Pu1verized Fuels: A Review of Theory and Experiment," Rev. Pure and Appl. Chem., Vol. 19, p. 81 (1969).

11. H. Kobayashi, "Devolatilization of Pulverized Coal at High Temperatures," Ph.D. Thesis, Massachusetts Institute of Technology, June, 1976.

12. N. Laurendeau, "Heterogeneous Kinetics of Coal Char Gasification and Combustion," Prog. Energy Comb. Sci.,Vo1. 4, pp. 221-270 (1978) 


\subsection{SUMMARY}

The first six months of this contract have been directed to improvements in the Stanford Flow Reactor and associated diagnostics, characterization of conditions within the reactor, and measurement of the oxidation reactivity of Montana Rosebud coal. Radial profiles of gas temperature, velocity, and $\mathrm{CO}_{2}$ concentration are uniform in the core of the flow, in accord with design specifications. Montana Rosebud was found to have a relatively high oxidation reactivity; for the larger particles $(\sim 60 \mu)$ and higher gas temperature ( $\sim 1500 \mathrm{~K}$ ) the reaction rate was diffusion limited. Marked qualitative differences in the oxidation behavior as a function of gas temperature were observed. The rapid early production of $\mathrm{CO}_{2}$ associated with volatile evolution at gas temperatures of about $1500 \mathrm{~K}$ did not occur at lower temperatures, for which the oxidation rate was more nearly independent of time. SEM analysis showed the development of a pronounced macropore structure during burnout. This structure is consistent.with preliminary data at gas temperatures of about $1500 \mathrm{~K}$ indicating a reactivity more nearly proportional to particle volume rather than to particle external surface area, in contrast to the predictions of some theories. 
BODYED BY TK JUN12 